\title{
BMJ Open Obstructive spirometry pattern and the risk of chronic kidney disease: analysis from the community-based prospective Ansan-Ansung cohort in Korea
}

\author{
Sang Hyuk Kim (D) , ${ }^{1}$ Hyeon Sam Kim, ${ }^{2}$ Hyang Ki Min $\left(D,{ }^{2}\right.$ Sung Woo Lee ${ }^{2}$
}

To cite: Kim SH, Kim HS, Min HK, et al. Obstructive spirometry pattern and the risk of chronic kidney disease: analysis from the community-based prospective Ansan-Ansung cohort in Korea. BMJ Open 2021;11:e043432. doi:10.1136/ bmjopen-2020-043432

- Prepublication history and additional material for this paper is available online. To view these files, please visit the journal online (http://dx.doi.org/10. 1136/bmjopen-2020-043432).

Received 03 August 2020 Revised 25 January 2021 Accepted 11 February 2021

Check for updates

(C) Author(s) (or their employer(s)) 2021. Re-use permitted under CC BY-NC. No commercial re-use. See rights and permissions. Published by BMJ.

${ }^{1}$ Medical Service Corps of 2nd Armored Brigade, Republic of Korea Army, Paju, South Korea ${ }^{2}$ Department of Internal Medicine, Nowon Eulji Medical center, Eulji University, Seoul, South Korea

Correspondence to Professor Sung Woo Lee; neplsw@gmail.com

\section{ABSTRACT}

Objective There have been limited studies on the relationship between obstructive spirometry pattern and the development of chronic kidney disease (CKD). We investigated the association between obstructive spirometry pattern and incident CKD development in a large-scale prospective cohort study.

Methods We reviewed the data of 7960 non-CKD adults aged 40-69 years who participated in the AnsungAnsan cohort, a prospective community-based cohort study. Prebronchodilation results for the ratio of forced expiratory volume per $1 \mathrm{~s}$ (FEV1) to forced vital capacity (FVC) were used as the primary exposure. The primary outcome was incident CKD, defined as the first event of an estimated glomerular filtration rate $<60 \mathrm{~mL} / \mathrm{min} / 1.73 \mathrm{~m}^{2}$. HRs and 95\% Cls were calculated using multivariate Cox proportional hazard regression analysis.

Results Over a mean follow-up period of 11.7 years, incident CKD developed in 511 subjects (6.4\%). An increase of 0.1 in FEV1/FVC was associated with a decreased risk of incident CKD (HR 0.76, 95\% Cl 0.68 to $0.84, p<0.001)$. Compared with the fourth quartile, the $\mathrm{HR}(95 \% \mathrm{Cl})$ of the first quartile of FEV1/FVC ratio was 1.81 (1.39 to 2.36, $p<0.001$ ). In the restricted cubic spline curve, the renal hazard associated with a decreased FEV1/ FVC ratio was evident at FEV1/FVC values $<0.80$, showing a U-shaped relationship. In subgroup analysis, the renal hazard associated with a decreased FEV1/FVC ratio was particularly evident in people without metabolic syndrome ( $p$ for interaction $=0.018$ ).

Conclusion Decreased FEV1/FVC ratio was independently associated with an increased risk of incident CKD development, particularly in people without metabolic syndrome. Future studies need to be conducted to confirm these results.

\section{INTRODUCTION}

Airway obstruction which is commonly found in chronic respiratory diseases, such as chronic obstructive pulmonary disease (COPD) and bronchial asthma (BA), can be objectively measured by pulmonary function tests. ${ }^{12}$ Obstructive spirometry pattern is defined by a combination of the results of spirometry. ${ }^{3}$ The main parameter that represents obstructive spirometry pattern is
Strengths and limitations of this study

- The strength of our study is the prospective nature of this study with a large number of participants.

- Our study is the only study to investigates the association between lung function and chronic kidney disease development using a non-linear analytic method.

- The limitations are the observational nature of our study and only pre-bronchodilator measurements were used for analysis.

- Another limitation is that generalisation is limited because the study was conducted in a single country.

the ratio of forced expiratory volume per $1 \mathrm{~s}$ (FEV1) to forced vital capacity (FVC). ${ }^{4}$ Many studies have revealed that lower FEV1/FVC ratios are associated with increased comorbidities and mortality. ${ }^{5-8}$ Decreased FEV1/ FVC ratios are also associated with increased incidence of atrial fibrillation, ${ }^{5}$ heart failure ${ }^{6}$ and type 2 diabetes mellitus. ${ }^{7}$

Chronic kidney disease (CKD) is one of the major chronic diseases in modern society, causing substantial medical expenses, chronic disease morbidity and mortality. ${ }^{9}$ According to the 2011-2013 report, the total prevalence of CKD in adults aged more than 20 years was $8.2 \%$ in Korea. ${ }^{10}$ The prevalence and incidence of CKD has been increasing worldwide, particularly in developing countries. ${ }^{11}$ In addition, CKD is related to an increased incidence of mental disorders, including depression, dementia and Parkinson's disease. ${ }^{12-14}$ As a result, degradation of quality of life was commonly found in the CKD population. ${ }^{15}$ Therefore, identification of factors associated with CKD and early intervention may be helpful in promoting public health. ${ }^{16}$

Several recent studies have reported the association between obstructive airway diseases and CKD ${ }^{17-19}$ Furthermore, the findings of obstructive spirometry pattern may 
also be associated with CKD. ${ }^{20-22}$ Suzuki et al reported that the prevalence of CKD increased with an increase in the obstructive spirometry grade. ${ }^{20}$ Sumida $e t$ al analysed 14946 participants of the Atherosclerosis Risk in Communities study and reported that the incidence of end-stage renal disease was higher in the lowest quartile of FEV1/ FVC ratio than highest quartile with a hazard ratio (HR) and $95 \%$ confidence interval (CI) of 1.33 (1.03 to 1.73). ${ }^{21}$ Although one Korean study also suggested that decreased FEV1/FVC ratio was associated with an increased risk of incident CKD, it was based on a single-centre retrospective cohort, and the potential renal hazard associated with obstructive spirometry pattern needs to be tested in a prospective setting. ${ }^{22}$ The aim of this study was, therefore, to investigate the relationship between FEV1/FVC ratio and incident CKD using data from the community-based prospective Ansan-Ansung cohort in Korea.

\section{METHODS}

\section{Participants}

The Ansan-Ansung cohort was prospectively assessed to investigate factors affecting the incidence of chronic diseases in the Ansan (urban) and Ansung (rural) areas. The enrolled subjects were aged 40-69 years and lived in these two cities in Korea, and baseline measurements were performed between May 2001 and February 2003. Participants were examined biennially after the baseline measurement. This community-based prospective cohort study is ongoing, and the last follow-up was conducted in 2015-2016. More detailed information about the AnsanAnsung cohort can be found in previous reports. ${ }^{23}$ In total, 10030 people participated at the baseline. Out of 10030 subjects, we excluded 252 subjects with missing spirometry results, 114 subjects with missing smoking status, and 337 subjects with missing data for metabolic disorders. Of the remaining 9327 subjects, 186 subjects with prevalent CKD, 189 subjects with baseline proteinuria defined as $\geq 1+$ protein in dipstick urinalysis (URISCAN Pro II; YD Diagnostic Corp), 917 subjects missing serial creatinine measurements, and 75 subjects with prevalent chronic lung diseases were further excluded. Finally, 7960 subjects were included in this study for analysis (figure 1).

All data were completely anonymised prior to access. Our study was also checked using the Strengthening the Reporting of Observational Studies in Epidemiology Statement. ${ }^{24}$

\section{Exposure}

The main exposure of this study was the FEV1/FVC ratio, which was obtained by pre-bronchodilator testing using spirometry (VMAX2130; Sensormedics, Yorba, California, USA). FEV1 and FVC were measured three times and best scores were recorded by well-trained technicians. Per cent-predicted FEV1 and FVC values were used to calculate the FEV1/FVC ratio, and the predicted FEV1 and FVC values used to calculate per cent-predicted FEV1 and FVC values were derived from Korean formula. ${ }^{25}$
10,030 subjects enrolled in Ansan-Ansung cohort study

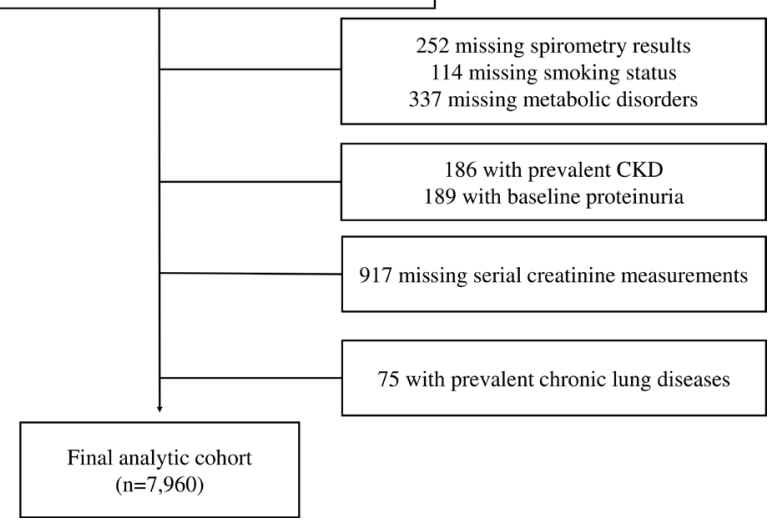

Figure 1 Flow chart of the study subject selection. CKD, chronic kidney disease.

\section{Outcome}

Estimated glomerular filtration rate (eGFR) was calculated using the CKD Epidemiology Collaboration equation. ${ }^{26}$ CKD was defined as eGFR $<60 \mathrm{~mL} / \mathrm{min} / 1.73 \mathrm{~m}^{2}$. Prevalent CKD was defined as eGFR $<60 \mathrm{~mL} / \mathrm{min} / 1.73 \mathrm{~m}^{2}$ at the baseline measurement and incident CKD, a main outcome of this study, was defined as the first event of eGFR $<60 \mathrm{~mL} / \mathrm{min} / 1.73 \mathrm{~m}^{2}$, which was confirmed at least two or more times and was maintained thereafter.

\section{Measurements and other definitions}

A standard interview regarding the participants' sociodemographic status and lifestyle was conducted by trained interviewers. High income was defined as the highest quintile of monthly household income ( $\geq 3$ million won a month). Blood pressure (BP) was measured using a standard mercury sphygmomanometer (BaumanometerStandby; W. A. Baum, Copiague, New York, USA), and the average $\mathrm{BP}$ on both arms was used as the representative BP measure. Body mass index (BMI) was calculated by dividing the weight by the square of the height $\left(\mathrm{kg} / \mathrm{m}^{2}\right)$. Waist circumference (WC) was measured at the narrowest point between the lower rib and the iliac crest (measured to the nearest $0.1 \mathrm{~cm}$ ). Blood samples were examined for fasting for at least 8 hours. Haemoglobin levels and white cell count (WCC) were analysed using enzymatic methods with ADVIA 120 (Bayer Diagnostics, Tarrytown, New York, USA). Fasting glucose (FG), triglyceride (TG), high-density lipoprotein cholesterol (HDL-C), C reactive protein (CRP), serum creatinine and blood urea nitrogen levels were measured using ADVIA 1650 (Siemens, Tarrytown, New York, USA). Five components of metabolic syndrome (MetS) were defined according to the recommendations of the International Diabetes Federation. ${ }^{27}$ First, elevated BP was defined as a systolic BP $\geq 130 \mathrm{~mm}$ $\mathrm{Hg}$, a diastolic $\mathrm{BP} \geq 85 \mathrm{~mm} \mathrm{Hg}$, treatment with antihypertensive drugs, or a previous diagnosis of hypertension by a physician. Second, elevated FG was defined as an FG level of $\geq 100 \mathrm{mg} / \mathrm{dL}$, treatment with insulin or oral antidiabetic drugs, or a previous diagnosis of diabetes 
by a physician. Third, increased TG was defined as TG $\geq 150 \mathrm{mg} / \mathrm{dL}$, treatment with anti-dyslipidemic drugs, or a previous diagnosis of dyslipidaemia by a physician. Fourth, reduced HDL-C levels were defined as HDL-C $<40 \mathrm{mg} / \mathrm{dL}$ in men and $<50 \mathrm{mg} / \mathrm{dL}$ in women. Finally, central obesity was defined as $\mathrm{WC} \geq 90 \mathrm{~cm}$ in men and $\geq 80 \mathrm{~cm}$ in women. MetS was defined as three or more of the five MetS components. ${ }^{28}$

\section{Statistical analyses}

All statistical analyses were performed using R V.3.6.2 ( $\mathrm{R}$ core Team 2019; R foundation for Statistical Computing, Vienna, Austria). Histograms and Q-Q plots were used to evaluate the normality of continuous variables. Normally distributed continuous variables were expressed as mean \pm SD. Non-normally distributed continuous variables were described as medians with IQR. The $p$ trend was analysed using linear regression for the normally distributed continuous variables, Jonckheere-Terpstra test for the non-normally distributed continuous variables, and the Cochran-Armitage test for the categorical variables. Survival curves were analysed using Kaplan-Meier estimates, and differences among groups were tested using the log-rank test. HRs and 95\% CIs were calculated using Cox proportional hazards regression analysis. Both analyses were performed with the 'survival' package. In the Kaplan-Meier survival curve, the mean survival time of each FEV1/FVC ratio quartile group was truncated at 14 years and analysed using the restricted mean survival time function with the 'survRM2' package. The proportional hazards assumption was verified by goodness-of-fit tests. All variables except age satisfied the proportional risk assumption. As a result, Cox proportional hazard regression analysis was performed without adjustment for age and Kaplan-Meier survival curve by age was presented (online supplemental figure S1). Potential non-linear relationships between obstructive spirometry pattern and incident CKD were evaluated using restricted cubic spline curve analysis with the 'rms' package. A $p<0.05$ was considered statistically significant. Subgroup analysis was performed on clinically important variables, and continuous variables were divided into median values. Sensitivity analysis was presented using multivariate Cox regression analysis for per cent-predicted FEV1 and FVC.

\section{Patient and public involvement}

Cohort data managed by the Korea Center for Disease Control and Prevention was provided anonymously. Patient and public were not involved in the design of this study. The result will not be disseminated to participants.

\section{RESULTS}

The 7960 subjects had a mean \pm SD age of $51.7 \pm 8.7$ years, and the proportions of men and current smokers were $48.2 \%$ and $41.1 \%$, respectively. Mean \pm SD BMI, WC, systolic $\mathrm{BP}$, diastolic BP, and HDL-C level were $24.6 \pm 3.1 \mathrm{~kg} / \mathrm{m}^{2}$, $82.6 \pm 8.7 \mathrm{~cm}, 120.9 \pm 18.1 \mathrm{~mm} \mathrm{Hg}, 80.2 \pm 11.4 \mathrm{~mm} \mathrm{Hg}$, and
$44.7 \pm 9.9 \mathrm{~mL} / \mathrm{dL}$, respectively, and median (IQR) of FG and TG levels were 82 (77-90) $\mathrm{mg} / \mathrm{dL}$ and 134 (99-187) $\mathrm{mg} / \mathrm{dL}$, respectively. The mean $\pm \mathrm{SD}$ of FEV1/FVC ratio, FEV1 and FVC were $0.80 \pm 0.08,96.9 \% \pm 14.1 \%$-predicted, and $96.9 \% \pm 13.1 \%$-predicted, respectively. Mean \pm SD baseline creatinine was $0.8 \pm 0.2 \mathrm{~mL} / \mathrm{min} / 1.73 \mathrm{~m}^{2}$. During a mean 11.7 years' follow-up, incident CKD developed in 511 subjects $(6.4 \%)$.

The first through fourth quartiles of the FEV1/FVC ratio were $<0.76,0.76-0.80,0.81-0.84$ and $\geq 0.85$, respectively. The baseline characteristics of the study according to the FEV1/FVC ratio quartiles are depicted in table 1. As the FEV1/FVC ratio quartile decreased, the proportions of men and current smokers increased, while the proportions of high-income and college graduates decreased. Although BMI and the HDL-C level decreased, systolic $\mathrm{BP}$, diastolic $\mathrm{BP}$ and $\mathrm{WC}$ increased as the $\mathrm{FEV} 1 / \mathrm{FVC}$ ratio quartile decreased. With the reduction in the FEV1/FVC ratio quartile, WCC, CRP, haemoglobin, creatinine and FVC increased, while FEV1 decreased.

We explored the potential hazard of the FEV1/FVC ratio quartile on the development of incident CKD. In the Kaplan-Meier survival curve (figure 2), the mean (95\% CI) CKD-free survival was 13.4 (13.3-13.5) years in Q1, 13.6 (13.5-13.6) years in Q2, $13.7(13.7-13.8)$ years in Q3 and 13.7 (13.6-13.8) years in Q4 (log-rank $\mathrm{p}<0.001)$. In multivariate Cox proportional hazard regression analysis (table 2), a 0.1-unit increase in FEV1/FVC ratio was associated with decreased hazard of incident CKD development: HR $(95 \% \mathrm{CI})$ of 0.73 (0.66 to $0.82, \mathrm{p}<0.001)$. Compared with the fourth quartile, the HR $(95 \% \mathrm{CI})$ of the first quartile of the FEV1/FVC ratio was 1.81 (1.39 to $2.36, \mathrm{p}<0.001)$. In restricted cubic spline curve analysis (figure 3), as FEV1/FVC ratio decreased, HR $(95 \%$ CI) for incident CKD development increased, showing a U-shaped relationship and the negative relationship was obvious for FEV1/FVC $<0.80$. However, unlike the FEV1/ FVC ratio, FEV1 was not associated with the development of incident CKD in the sensitivity analysis (online supplemental table S1).

In the subgroup analysis, MetS modified the effect of the FEV1/FVC ratio on incident CKD development (figure 4). In detail, although an increased FEV1/FVC ratio was not associated with incident CKD development in people with MetS, it was independently associated with incident CKD development in those without MetS. There were no subgroups showing statistically significant effect modification. However, younger age, low baseline eGFR, and raised FG were not valid subgroups for the for the relationship between FEV1/FVC ratio and CKD development (online supplemental table S2).

\section{DISCUSSION}

Obstructive lung disease and CKD are both important chronic diseases in the modern world. ${ }^{9}{ }^{29}$ Several recent studies have shown the relationship between obstructive lung disease and CKD. ${ }^{17}{ }^{30}$ Chen and Liao reported 
Table 1 Clinical characteristics of the study population according to the FEV1/FVC ratio quartile

FEV1/FVC ratio groups $(\mathrm{n}=7960)$

\begin{tabular}{|c|c|c|c|c|c|}
\hline & $\begin{array}{l}1 Q:<0.76 \\
(n=1935)\end{array}$ & $\begin{array}{l}2 Q: 0.76-0.80 \\
(n=2027)\end{array}$ & $\begin{array}{l}3 Q: 0.81-0.84 \\
(n=2088)\end{array}$ & $4 Q: \geq 0.85(n=1910)$ & P-trend \\
\hline Age (years) & $55.93 \pm 8.66$ & $52.41 \pm 8.50^{*}$ & $50.09 \pm 7.98^{*} \dagger$ & $48.47 \pm 7.81^{\star} \dagger \ddagger$ & $<0.001$ \\
\hline High income, n (\%) & 230 (11.89) & $384(18.94)^{*}$ & $433(20.74)^{*}$ & $383(20.05)^{\star}$ & $<0.001$ \\
\hline College graduate, $\mathrm{n}(\%)$ & $189(9.77)$ & $283(13.96)^{\star}$ & $360(17.24)^{\star} \dagger$ & $273(14.29)^{*} \ddagger$ & $<0.001$ \\
\hline $\mathrm{SBP}(\mathrm{mm} \mathrm{Hg})$ & $123.80 \pm 18.41$ & $121.24 \pm 17.82^{*}$ & $119.66 \pm 17.96^{\star} \dagger$ & $118.80 \pm 17.92^{*} \dagger$ & $<0.001$ \\
\hline $\mathrm{DBP}(\mathrm{mm} \mathrm{Hg})$ & $81.72 \pm 11.09$ & $80.32 \pm 11.16^{\star}$ & $79.65 \pm 11.40^{\star}$ & $78.98 \pm 11.65^{\star} \dagger$ & $<0.001$ \\
\hline Waist circumference (cm) & $83.31 \pm 8.04$ & $83.60 \pm 8.44$ & $82.54 \pm 8.73^{*} \dagger$ & $80.96 \pm 9.20^{*} \dagger \ddagger$ & $<0.001$ \\
\hline Fasting glucose (mg/dL) & $82(77-90)$ & $82(77-91)$ & $82(78-90)$ & $82(77-89)$ & 0.390 \\
\hline Haemoglobin $(g / L)$ & $139.70 \pm 14.46$ & $137.36 \pm 15.70^{*}$ & $134.48 \pm 16.34^{*} \dagger$ & $133.19 \pm 15.33^{*} \dagger$ & $<0.001$ \\
\hline WCC $\left(\times 10^{9} / L\right)$ & $6.70 \pm 1.83$ & $6.51 \pm 1.77^{*}$ & $6.43 \pm 1.73^{*}$ & $6.38 \pm 1.73^{*} \dagger$ & $<0.001$ \\
\hline $\mathrm{CRP}(\mathrm{mg} / \mathrm{dL})$ & $0.15(0.07-0.26)$ & $0.14(0.06-0.23)^{\star}$ & $0.13(0.06-0.24)^{\star}$ & $0.14(0.06-0.23)^{\star}$ & $<0.001$ \\
\hline FEV1 (\%-predicted) & $87.89 \pm 14.59$ & $97.35 \pm 12.58^{*}$ & $100.25 \pm 12.18^{*} \dagger$ & $101.98 \pm 12.53^{*} \dagger \ddagger$ & $<0.001$ \\
\hline FVC (\%-predicted) & $98.24 \pm 14.05$ & $98.24 \pm 12.90$ & $97.22 \pm 12.24$ & $93.96 \pm 12.72^{*} \dagger \ddagger$ & $<0.001$ \\
\hline
\end{tabular}

Values are expressed as mean \pm SD for normally distributed continuous variables, median and IQR for non-normally distributed variables and percentage for categorical variables. $P$ trend was analysed normally distributed continuous variables by ANOVA, for non-normally distributed continuous variable by Jonckheere-Terpstra tests, and for categorical variables by Cochran-Armitage test for trend. * $\dagger$ and $\ddagger$ meant $\mathrm{p}<0.05$ when compared with $<0.76,0.76-0.81,0.81-0.85$ groups of FEV1/FVC ratio, respectively, using Bonferroni post hoc analysis of one-way ANOVA for normally distributed continuous variables, Mann-Whitney $U$ tests for non-normally distributed continuous variable and $\chi^{2}$ tests for categorical variables.

ANOVA, analysis of variance; BMI, body mass index; CRP, C reactive protein; DBP, diastolic blood pressure; FEV1, forced expiratory volume in $1 \mathrm{~s}$; FVC, forced vital capacity; HDL, high density lipoprotein; SBP, systolic blood pressure; WCC, white cell count.

that the overall incidence of CKD was higher in the COPD group (287.52 per 104 person-years vs 470.9 per 104 person-years) ${ }^{30}$ Huang et al found that BA patients were more likely to develop CKD (HR 1.56, 95\% CI 1.48 to $1.64, \mathrm{p}<0.001) .{ }^{17}$ The FEV1/FVC ratio called the

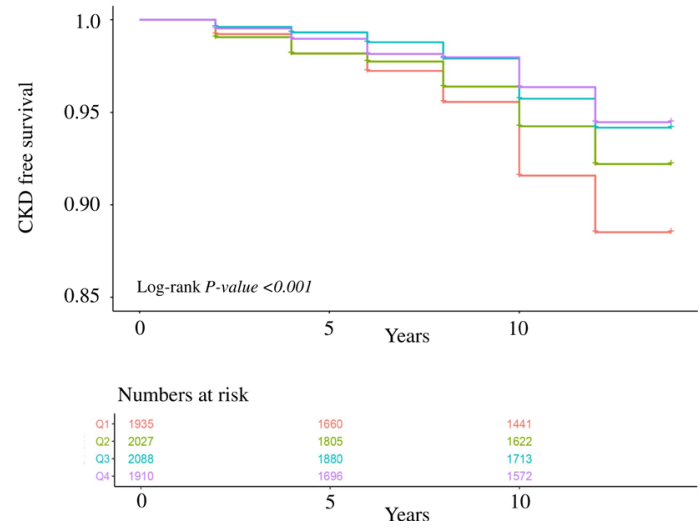

Figure 2 Kaplan-Meier CKD-free survival curves among four groups defined by the FEV1/FVC ratio. CKD, chronic kidney disease; FEV1, forced expiratory volume in 1s; FVC, functional vital capacity.
Tiffeneau-pinelli index, has been used worldwide as a screening index for diagnosing obstructive lung disease. The FEV1/FVC ratio is an easily applicable index because it does not require calculation of the predicted value. ${ }^{318}$ Since only a few studies have evaluated the usefulness of the FEV1/FVC ratio in predicting future incident CKD development, we performed the current study and identified that a decreased FEV1/FVC ratio was independently associated with incident CKD development in a community-dwelling general population.

In this study, a 0.1 unit increase in the FEV1/FVC ratio was associated with a $16 \%$ lower risk of developing incident CKD. In comparison with patients showing FEV1/FVC $\geq 0.85$ (highest quartile), those with an FEV1/FVC ratio $<0.76$ (lowest quartile) showed a $35 \%$ higher risk of developing incident CKD. However, those in the second and third quartiles did not show a statistically significant renal hazard, suggesting a non-linear relationship between the FEV1/FVC ratio and incident CKD development. Therefore, we performed restricted cubic spline curve analysis and found that the renal hazard of association with decreased FEV1/FVC was evident at FEV1/FVC $<0.80$. 
Table 2 Hazard of FEV1/FVC ratio on incident CKD development

\begin{tabular}{|c|c|c|c|}
\hline & Univariate & Model 1 & Model 2 \\
\hline & HR (95\% CI, p value) & HR (95\% Cl, p value) & HR (95\% Cl, p value) \\
\hline FEV1/FVC ratio: 0.1-unit increase & $0.69(0.63$ to $0.76,<0.001)$ & $0.65(0.59$ to $0.72,<0.001)$ & $0.73(0.66$ to $0.82,<0.001)$ \\
\hline $1 Q:<0.76(n=1935)$ & $2.13(1.66$ to $2.75,<0.001)$ & $2.35(1.82$ to $3.05,<0.001)$ & $1.81(1.39$ to $2.36,<0.001)$ \\
\hline 2Q: $0.76-0.80(n=2027)$ & $1.45(1.11$ to $1.89,0.006)$ & $1.49(1.14$ to $1.95,0.003)$ & $1.31(1.00$ to $1.72,0.047)$ \\
\hline $4 Q: \geq 0.85(n=1910)$ & 1.00 (reference) & 1.00 (reference) & 1.00 (reference) \\
\hline
\end{tabular}

Model 1: adjustment for sex and BMI. Model 2: model 1+adjustment for college graduate, high income, smoking status, systolic and diastolic BP, waist circumference, fasting glucose, triglyceride, HDL-cholesterol, creatinine, haemoglobin level, WCC, and CRP.

$\mathrm{BMI}$, body mass index; BP, blood pressure; CKD, chronic kidney disease; CRP, C reactive protein; FEV1, forced expiratory volume in 1s; FVC, forced vital capacity; HDL, high density lipoprotein; WCC, white cell count.

Furthermore, the renal hazard was increased proportionally with the decrease in FEV1/FVC, suggesting that FEV1/FVC can be used not only as a screening index, but also as a severity index, particularly in predicting future CKD development.

In contrast, however, per cent-predicted FEV1 which is traditionally used as a severity index for obstructive lung disease, was not associated with incident CKD development. This may be because of possible inaccuracies in the prediction method attribute to race, age and gender. ${ }^{31}$ We used the formula proposed in 2005 based on the Korean population, but the demographics of Korea have

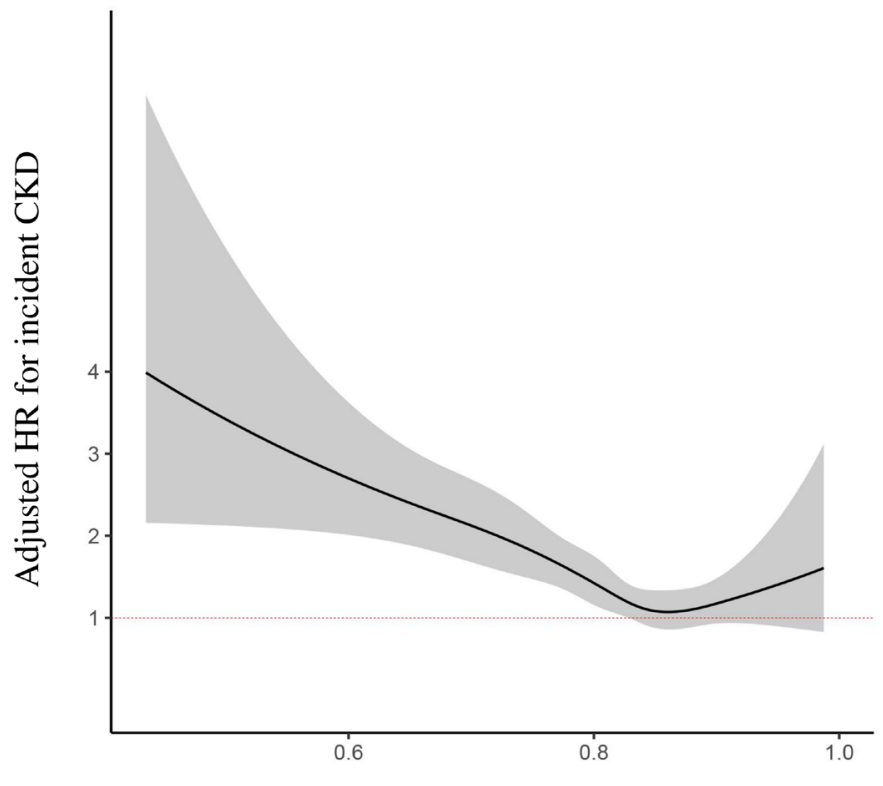

FEV1/FVC ratio

Figure 3 Restricted cubic splines curve of Cox proportional hazards regression analysis according to the FEV1/FVC ratio. All covariates of model 2 shown in table 2 were used for adjustment. The solid line indicates the calculated line of association between the FEV1/FVC ratio and estimated HR. The shaded region represents the $95 \% \mathrm{Cls}$ for value of HR according to the FEV1/FVC ratio. CKD, chronic kidney disease; FEV1, forced expiratory volume in 1s; FVC, functional vital capacity. been changed dramatically over the last 15 years. Thus, a new estimation formula based on new demographics will be needed. ${ }^{32}$ In addition, the ageing process and underlying diseases can falsely reduce FEV1 values due to respiratory muscle weakness, but the FEV1/FVC ratio was not affected by those confounders. ${ }^{33}$ Therefore, for a population with a low prevalence of airway obstruction, including this cohort, the FEV1/FVC ratio may be a more suitable index for predicting incident CKD than absolute FEV1 values. The FEV1/FVC ratio was particularly evident in groups without metabolic derangements. This means that spirometry patterns in individuals with metabolic disorders may differ from those in healthy population. We propose that FEV1/FVC ratio can be used as a spirometric index to be associated with future CKD development in a relatively healthy population.

To date, there have been no exact mechanisms for the potential renal hazard of airway obstruction. One possible explanation is the chronic hypoxia induced by airway obstruction. Chronic hypoxia may cause hypoxic renal damage, which is related to a decline in kidney



Figure 4 Subgroup analysis for the relationship between the FEV1/FVC ratio and the risk of incident CKD. Adjusted beta and $95 \% \mathrm{Cl}$ were analysed using Cox proportional hazards regression analysis. All covariates of model two shown in table 2 were used to adjustment. BMI, body mass index; $\mathrm{CKD}$, chronic kidney disease; CRP, $\mathrm{C}$ reactive protein; eGFR, estimated glomerular filtration rate; FEV1, forced expiratory volume in 1s; FVC, functional vital capacity; MetS, metabolic syndrome; WCC, white cell count. 
function. ${ }^{34}$ Atherosclerosis, a risk factor for CKD, is also associated with chronic hypoxia. ${ }^{35}$ The systemic inflammation in obstructive lung diseases, including increased levels of tumour necrosis factor $\alpha$ and interleukin 6 , may cause vascular calcification and protein-energy wasting, which can ultimately result in CKD development. ${ }^{36}$

Our study has several strengths. First, to our knowledge, this is the first prospective study using the FEV1/FVC ratio as the main index to predict CKD development. Second, a large number of participants and many confounders for the incident CKD were adjusted in this study. Third, using a non-linear analytic method, we found that incident CKD and the FEV1/FVC ratio had a U-shaped relationship. The upper limit of FEV1/FVC is not clear, but most of those with FEV1/FVC above 0.9 had a decreased FVC \% predicted. Neuromuscular disorders may cause high FEV1/FVC and be associated with incident CKD. Further study will be needed to clarify the clinical significance of high FEV1/FVC. This study also had several limitations. First, this was an observational study. Therefore, a causal relationship could not be ascertained, and the results should be interpreted with caution. Second, because of the large number of participants, we only obtained prebronchodilator measurements. Thirds, age was not included in the adjustment of Cox proportional hazard regression analysis. Age cannot be adjusted due to extreme violation of the proportional risk assumption. However, age was used to adjust for incident CKD. The superiority of further adjustment for already adjusted variable is not clear. Repeated adjustment of same variable can cause bias. ${ }^{37}$ Because of the low prevalence of airway diseases, however, we assumed that this limitation has little effect on the study results. Finally, the generalisability of the results is limited because the study was conducted in a single country with a single ethnicity.

In conclusion, decreased FEV1/FVC ratio was an independent risk factor for future CKD development. The relationship of this findings with incident CKD development was particularly valid in a relatively healthy population, suggesting that it may serve as an early predictor for CKD development. Future studies need to be conducted to confirm the results of this study.

Acknowledgements We would like to express our sincere appreciation to conduct Ansan-Ansung cohort (Grant No: NRF-2016R1A6A3A11933465).

Contributors Conceptualisation, SWL; Data curation/Formal analysis, SHK; Investigation/Methodology, HSK; Writing—original draft, SHK; Writing—review and editing-HKM; Supervision/Validation—SWL. All authors read and approved the final manuscript.

Funding This study was supported by the National Research Foundation of Korea (NRF) grant funded by the Korean government (MIST) (Grant No: NRF-2016R1A6A3A11933465).

Competing interests None declared.

Patient consent for publication Not required.

Ethics approval The Ansan-Ansung cohort complied with the Declaration of Helsinki. All participants provided informed consent and ethical approval was obtained from the institutional review boards of the Nowon Eulji Medical Center, Eulji University (IRB Number: 2019-06-014).

Provenance and peer review Not commissioned; externally peer reviewed.
Data availability statement Data are fully available on reasonable request.

Supplemental material This content has been supplied by the author(s). It has not been vetted by BMJ Publishing Group Limited (BMJ) and may not have been peer-reviewed. Any opinions or recommendations discussed are solely those of the author(s) and are not endorsed by BMJ. BMJ disclaims all liability and responsibility arising from any reliance placed on the content. Where the content includes any translated material, BMJ does not warrant the accuracy and reliability of the translations (including but not limited to local regulations, clinical guidelines, terminology, drug names and drug dosages), and is not responsible for any error and/or omissions arising from translation and adaptation or otherwise.

Open access This is an open access article distributed in accordance with the Creative Commons Attribution Non Commercial (CC BY-NC 4.0) license, which permits others to distribute, remix, adapt, build upon this work non-commercially, and license their derivative works on different terms, provided the original work is properly cited, appropriate credit is given, any changes made indicated, and the use is non-commercial. See: http://creativecommons.org/licenses/by-nc/4.0/.

\section{ORCID iDs}

Sang Hyuk Kim http://orcid.org/0000-0002-0410-8524

Hyang Ki Min http://orcid.org/0000-0002-5883-234X

\section{REFERENCES}

1 Nussbaumer-Ochsner Y, Rabe KF. Systemic manifestations of COPD. Chest 2011;139:165-73.

2 Rodrigo GJ, Rodrigo C, Hall JB. Acute asthma in adults: a review. Chest 2004;125:1081-102.

3 Barreiro TJ, Perillo I. An approach to interpreting spirometry. Am Fam Physician 2004;69:1107-14.

4 Vaz Fragoso CA, Concato J, McAvay G, et al. The ratio of FEV1 to $F V C$ as a basis for establishing chronic obstructive pulmonary disease. Am J Respir Crit Care Med 2010;181:446-51.

$5 \mathrm{Li} \mathrm{J}$, Agarwal SK, Alonso A, et al. Airflow obstruction, lung function, and incidence of atrial fibrillation: the Atherosclerosis risk in communities (ARIC) study. Circulation 2014;129:971-80.

6 Agarwal SK, Heiss G, Barr RG, et al. Airflow obstruction, lung function, and risk of incident heart failure: the Atherosclerosis risk in communities (ARIC) study. Eur J Heart Fail 2012;14:414-22.

7 Yeh H-C, Punjabi NM, Wang N-Y, et al. Cross-sectional and prospective study of lung function in adults with type 2 diabetes: the Atherosclerosis risk in communities (ARIC) study. Diabetes Care 2008;31:741-6.

8 Mannino DM, Buist AS, Petty TL, et al. Lung function and mortality in the United States: data from the first National health and nutrition examination survey follow up study. Thorax 2003;58:388-93.

$9 \mathrm{Kim} \mathrm{S-H}$, Jo M-W, Go D-S, et al. Economic burden of chronic kidney disease in Korea using national sample cohort. $J$ Nephrol 2017;30:787-93.

10 Park Jl, Baek H, Jung HH. Prevalence of chronic kidney disease in Korea: the Korean National health and nutritional examination survey 2011-2013. J Korean Med Sci 2016;31:915-23.

11 Nugent RA, Fathima SF, Feigl AB, et al. The burden of chronic kidney disease on developing nations: a 21st century challenge in global health. Nephron Clin Pract 2011;118:c269-77.

12 Palmer S, Vecchio M, Craig JC, et al. Prevalence of depression in chronic kidney disease: systematic review and meta-analysis of observational studies. Kidney Int 2013;84:179-91.

13 Lin H-L, Lin H-C, Chen Y-H. Increased risks of parkinsonism in the 3 years after chronic renal failure. Int J Clin Pract 2012;66:499-503.

14 Sasaki Y, Marioni R, Kasai M, et al. Chronic kidney disease: a risk factor for dementia onset: a population-based study. The Osaki-Tajiri project. J Am Geriatr Soc 2011;59:1175-81.

15 Mucsi I, Kovacs AZ, Molnar MZ, et al. Co-morbidity and quality of life in chronic kidney disease patients. J Nephrol 2008;21(Suppl 13):S84.

16 Levin A, Stevens PE. Early detection of CKD: the benefits, limitations and effects on prognosis. Nat Rev Nephrol 2011;7:446-57.

17 Huang H-L, Ho S-Y, Li C-H, et al. Bronchial asthma is associated with increased risk of chronic kidney disease. BMC Pulm Med 2014;14:80.

18 Singh D, Agusti A, Anzueto A, et al. Global strategy for the diagnosis, management, and prevention of chronic obstructive lung disease: the gold science Committee report 2019. Eur Respir J 2019;53. doi:10.1183/13993003.00164-2019. [Epub ahead of print: 18 May 2019].

19 Gaddam S, Gunukula SK, Lohr JW, et al. Prevalence of chronic kidney disease in patients with chronic obstructive pulmonary 
disease: a systematic review and meta-analysis. BMC Pulm Med 2016:16:158.

20 Suzuki N, Matsuki E, Araumi A, et al. Association among chronic kidney disease, airflow limitation, and mortality in a communitybased population: the Yamagata (Takahata) study. Sci Rep 2020;10:5570.

21 Sumida K, Kwak L, Grams ME, et al. Lung function and incident kidney disease: the Atherosclerosis risk in communities (ARIC) study. Am J Kidney Dis 2017;70:675-85.

22 Kim SK, Bae JC, Baek J-H, et al. Is decreased lung function associated with chronic kidney disease? A retrospective cohort study in Korea. BMJ Open 2018;8:e018928.

$23 \mathrm{Kim}$ Y, Han B-G, KoGES group. Cohort profile: the Korean genome and epidemiology study (KoGES) Consortium. Int J Epidemiol 2017:46:e20.

24 von Elm E, Altman DG, Egger M, et al. The strengthening the reporting of observational studies in epidemiology (STROBE) statement: guidelines for reporting observational studies. Ann Intern Med 2007;147:573-7.

25 Choi JK, Paek D, Lee JO. Normal predictive values of spirometry in Korean population. Tuberc Respir Dis 2005;58:230-42.

26 Levey AS, Stevens LA, Schmid CH, et al. A new equation to estimate glomerular filtration rate. Ann Intern Med 2009;150:604-12.

27 Alberti KGMM, Zimmet P, Shaw J. Metabolic syndrome--a new world-wide definition. A Consensus Statement from the International Diabetes Federation. Diabet Med 2006;23:469-80.

28 Alberti KGMM, Eckel RH, Grundy SM, et al. Harmonizing the metabolic syndrome: a joint interim statement of the International diabetes Federation Task force on epidemiology and prevention; National heart, lung, and blood Institute; American heart association; world heart Federation; international atherosclerosis Society; and international association for the study of obesity. Circulation 2009;120:1640-5.

29 Mannino DM, Buist AS. Global burden of COPD: risk factors, prevalence, and future trends. Lancet 2007:370:765-73.

30 Chen C-Y, Liao K-M. Chronic obstructive pulmonary disease is associated with risk of chronic kidney disease: a nationwide casecohort study. Sci Rep 2016;6:25855.

31 Stanojevic S, Wade A, Stocks J. Reference values for lung function: past, present and future. Eur Respir J 2010;36:12-19.

32 Han J-S, Lee J-W, change D. Demographic change, human capital, and economic growth in Korea. Japan World Econ 2020;53:100984.

33 Santos RBD, Fraga AS, Coriolano MdasGWdeS, et al. Respiratory muscle strength and lung function in the stages of Parkinson's disease. J Bras Pneumol 2019;45:e20180148.

34 Tanaka S, Tanaka T, Nangaku M. Hypoxia as a key player in the AKIto-CKD transition. Am J Physiol Renal Physiol 2014;307:F1187-95.

35 Savransky V, Nanayakkara A, Li J, et al. Chronic intermittent hypoxia induces atherosclerosis. Am J Respir Crit Care Med 2007;175:1290-7.

36 Carrero JJ, Stenvinkel P. Persistent inflammation as a catalyst for other risk factors in chronic kidney disease: a hypothesis proposal. Clin J Am Soc Nephrol 2009;4(Suppl 1):S49-55.

37 Schisterman EF, Cole SR, Platt RW. Overadjustment bias and unnecessary adjustment in epidemiologic studies. Epidemiology 2009;20:488-95. 